\section{Regards sur l'économie allemande}

Bulletin économique du CIRAC

$85 \mid 2008$

Varia

\title{
Transports : fret et trafic passagers en hausse en
}

2007

\section{Solène Hazouard}

\section{(2) OpenEdition}

12 Journals

Édition électronique

URL : http://journals.openedition.org/rea/517

DOI : 10.4000/rea.517

ISBN : 978-2-8218-0866-9

ISSN : 1965-0787

\section{Éditeur}

CIRAC

Édition imprimée

Date de publication : 1 mars 2008

Pagination : 37-38

ISSN : 1156-8992

\section{Référence électronique}

Solène Hazouard, «Transports : fret et trafic passagers en hausse en 2007 », Regards sur l'économie allemande [En ligne], 85 | mars 2008, document 2, mis en ligne le 01 mars 2010, consulté le 15 septembre 2020. URL : http://journals.openedition.org/rea/517

Ce document a été généré automatiquement le 15 septembre 2020.

(c) CIRAC 


\title{
Transports : fret et trafic passagers en hausse en 2007
}

\author{
Solène Hazouard
}

\section{Le fret a augmenté de 4,8\% l'an dernier}

1 L'an passé, le volume de fret tous modes de transport confondus s'est accru de 4,8\%, selon Destatis. Les hausses les plus nettes ont été constatées au niveau du fret aérien $(+5,4 \%)$, ainsi qu'au niveau du fret routier $(+5,5 \%)$ qui représente à lui seul $77 \% \mathrm{du}$ transport de marchandises tous modes confondus. L'acheminement des marchandises par containers a contribué nettement à l'augmentation des volumes de fret ferroviaire et maritime : il a progressé à lui seul de $12 \%$ sur les rails et en mer.

2 L'aérien a connu quant à lui une croissance moins prononcée que lors des années précédentes, imputable notamment à un ralentissement dans la progression des échanges avec l'Asie. Dans ce domaine toujours, les principaux partenaires commerciaux de l'Allemagne demeurent de loin l'Union Européenne et les Etats-Unis, contribuant respectivement à hauteur de 17 et $18 \%$ au fret importé et de 20 et $23 \%$ au fret exporté. Quant aux échanges avec les pays de l'UE, ils continuent de croître: $+13,3 \%$ pour la France, $+10,4 \%$ pour la Grèce, $+33 \%$ pour le Portugal, $+27,9 \%$ pour la Pologne ou encore $+213,4 \%$ pour la Bulgarie. Enfin, pour ce qui est de la progression du fret acheminé vers l'Allemagne, la France et la Pologne se situent largement au-dessus de la moyenne de l'UE $(+5,1 \%)$ avec une performance de respectivement $+10,9 \%$ et $+90 \%$.

Volume de fret en Allemagne en 2007

\begin{tabular}{|l|c|c|c|c|}
\hline & $\begin{array}{c}\text { Nb de } \\
\text { Mode de transport }\end{array}$ & $\begin{array}{c}\text { Évol. } \\
2007 / 2006 \\
\text { (en millions) }\end{array}$ & $\begin{array}{c}\text { Tonnes- } \\
\text { kilomètres } \\
\text { (en milliards) }\end{array}$ & $\begin{array}{c}\text { Évol. } \\
2007 / 2006 \\
\text { (en \%) }\end{array}$ \\
\hline
\end{tabular}




\begin{tabular}{|l|c|c|c|c|}
\hline Routier & 3429,6 & 5,5 & 466,2 & 8,0 \\
\hline $\begin{array}{l}\text { dont: routier } \\
\text { domestique }\end{array}$ & 3039,4 & 4,8 & 307,3 & 6,4 \\
\hline Ferroviaire & 358,2 & 3,5 & 114,0 & 6,5 \\
\hline Fluvial & 247,4 & 1,6 & 65,0 & 1,6 \\
\hline Maritime & 311,1 & 4,0 & $n \cdot c$. & $n . c$. \\
\hline Oléoducs & 91,2 & $-3,2$ & 16,1 & 1,6 \\
\hline Aérien & 3,4 & 5,4 & $n \cdot c$. & $\mathbf{6 , 9}$ \\
\hline Total & $\mathbf{4 4 4 0 , 8}$ & $\mathbf{4 , 8}$ & $\mathbf{6 6 1 , 3}$ & \\
\hline
\end{tabular}

Source des données : Destatis (communiqué du 16-01-2008), www.destatis.de.

\section{Trafic passagers : $+0,3 \%$ en terrestre, $+6,2 \%$ en aérien}

Dans le même temps, le trafic passagers a progressé de $0,3 \%$ dans les modes de transport terrestre, le plus fort accroissement $(+1,8 \%)$ ayant été enregistré par les tramways et métros. Destatis estime à 10,3 milliards le nombre de trajets de liaisons urbaines effectués l'an dernier, pour une distance moyenne d'environ neuf kilomètres. Le trafic ferroviaire courtes et longues distances a stagné, voire baissé en raison notamment de la grève des conducteurs de train, venue ternir les résultats du quatrième trimestre : au total, près de 119 millions de passagers ont pris le train sur une longue distance l'an dernier, contre 120 millions en 2006. Le nombre de passagers dans le secteur aérien a crû de $6,2 \%$ au cours de l'année 2007, marquée également par la plus forte hausse du volume des liaisons intérieures de ces dix dernières années $(+6,3 \%)$.

Le transport de passagers en Allemagne en 2007

\begin{tabular}{|l|c|c|c|c|}
\hline Mode de transport & $\begin{array}{c}\text { Nb de } \\
\text { passagers } \\
\text { (en millions) }\end{array}$ & $\begin{array}{c}\text { Évol. } \\
\mathbf{2 0 0 7 / 2 0 0 6} \\
\text { (en \%) }\end{array}$ & $\begin{array}{c}\text { Personnes- } \\
\text { kilomètres } \\
\text { (en milliards) }\end{array}$ & $\begin{array}{c}\text { Évol. } \\
\text { 2007/2006 } \\
\text { (en \%) }\end{array}$ \\
\hline Bus et trains & 10411 & 0,3 & 132,0 & 0,5 \\
\hline dont : liaisons urbaines) $:$ & 10290 & 0,3 & 96,4 & 1,0 \\
\hline - rail & 2110 & 0,0 & 45,0 & 1,6 \\
\hline - tramway et métros & 3555 & 1,8 & 15,8 & 2,3 \\
\hline - bus & 5235 & $-0,6$ & 35,6 & $-0,4$ \\
\hline
\end{tabular}




\begin{tabular}{|l|c|c|c|c|}
\hline $\begin{array}{l}\text { Trafic autocars longue } \\
\text { distance }\end{array}$ & 2 & n.c. & 1,1 & $-9,7$ \\
\hline Trafic rail longue distance & 119 & $-0,9$ & 34,3 & $-0,5$ \\
\hline Trafic aérien & 163,5 & 6,2 & n.c. & n.c. \\
\hline
\end{tabular}

Source des données :Destatis (communiqués du 17-01-2008 et du 18-02-2008), www.destatis.de. *) Le nombre de passagers des liaisons urbaines est inférieur à la somme du nombre de passagers ventilé par les différents modes de transport assurant les liaisons urbaines du fait que Destatis tient compte, dans ces sous-catégories, des trajets effectués avec correspondance(s).

INDEX

Mots-clés : fret, train, transport 